\title{
Atmospheric Correction for Hyperspectral Ocean Color Retrieval with Application to the Hyperspectral Imager for the Coastal Ocean (HICO)
}

\author{
Amir Ibrahim ${ }^{1,2}$, Bryan Franz ${ }^{1}$, Ziauddin Ahmad ${ }^{1,3}$, Richard Healy ${ }^{1,4}$, Kirk Knobelspiesse ${ }^{1}$, Bo-Cai Gao ${ }^{5}$, \\ Chris Proctor $^{1,6}$, Peng-Wang Zhai ${ }^{7}$ \\ ${ }^{1}$ NASA Goddard Space Flight Center, Greenbelt, MD, ${ }^{2}$ Universities Space Research Association, Columbia, MD, ${ }^{3}$ Science \\ and Data Systems, Inc., Silver Spring, MD, ${ }^{4}$ Science Applications International Corp., Greenbelt, MD, ${ }^{5}$ Naval Research Lab, \\ Washington D.C., ${ }^{6}$ Science Systems and Applications Inc., Greenbelt, MD, ${ }^{7}$ University of Maryland Baltimore County, \\ Baltimore, $M D$
}

\begin{abstract}
The classical multi-spectral Atmospheric Correction (AC) algorithm is inadequate for the new generation of spaceborne hyperspectral sensors such as NASA's first hyperspectral Ocean Color Instrument (OCI) onboard the anticipated Plankton, Aerosol, Cloud, ocean Ecosystem (PACE) satellite mission. The AC process must estimate and remove the atmospheric path radiance contribution due to the Rayleigh scattering by air molecules and scattering by aerosols from the measured top-of-atmosphere (TOA) radiance, compensate for the absorption by atmospheric gases, and correct for reflection and refraction of the air-sea interface. In this work, we present and evaluate an improved AC for hyperspectral sensors developed within NASA's SeaWiFS Data Analysis System software package (SeaDAS). The improvement is based on combining the classical AC approach of multi-spectral capabilities to correct for the atmospheric path radiance, extended to hyperspectral, with a gas correction algorithm to compensate for absorbing gases in the atmosphere, including water vapor. The SeaDAS-hyperspectral version is capable of operationally processing the AC of any hyperspectral airborne or spaceborne sensor. The new algorithm development was evaluated and assessed using the Hyperspectral Imager for Coastal Ocean (HICO) scenes collected at the Marine Optical BuoY (MOBY) site, and other SeaWiFS Bio-optical Archive and Storage System (SeaBASS) and AERosol Robotic NETwork - Ocean Color (AERONET-OC) coastal sites. A hyperspectral vicarious calibration was applied to HICO, showing the validity and consistency of HICO's ocean color products. The hyperspectral AC capability is currently available in SeaDAS to the scientific community at https://oceancolor.gsfc.nasa.gov/. Keywords: Atmospheric Correction, Water Vapor, Ocean Color, Hyperspectral Remote Sensing, Hyperspectral Imager for Coastal Ocean (HICO), Vicarious Calibration, PACE
\end{abstract}

\section{Introduction}

Hyperspectral ocean color remote sensing is at an early stage with respect to algorithm development for atmospheric correction and the retrieval of ocean color products ("Pre-Aerosol, Clouds, and ocean Ecosys- 
tem (PACE) Mission Science Definition Team Report," 2012). The quantification of global chlorophyll concentration $[\mathrm{Chl}]$ and other inherent optical properties (IOPs), such as the absorption and backscattering coefficients of hydrosols, are derived using multispectral spaceborne radiometers such as NASA's Moderate Resolution Imaging Spectroradiometer (MODIS) (Esaias et al., 1998), currently operating from the Aqua spacecraft (MODISA), the Sea-viewing Wide Field-of-view Sensor (SeaWiFS) that operated from 1997 to 2010 (McClain et al., 2004) and the Visible Infrared Imaging Radiometer Suite (VIIRS) currently operating onboard the Suomi National Polar-orbiting Partnership (Suomi NPP) weather satellite (Murphy et al., 2001). Additionally, the European Space Agency (ESA) provided multi-spectral ocean color data from the Medium Resolution Imaging Spectrometer (MERIS) operated onboard Envisat, from 2002 to 2012 (Rast et al., 1999). Meanwhile, the Ocean and Land Colour Instrument (OLCI) currently operating onboard SENTINEL-3 platform is the successor to MERIS (Donlon et al., 2012). Utilizing radiometry in a few discrete bands that are spectrally located to detect variations in ocean constituents, these sensors have been successful in retrieving bulk concentrations of the phytoplankton pigment chlorophyll-a or associated phytoplankton absorption coefficients (Morel and Maritorena, 2001; O'Reilly et al., 1998; Werdell and Bailey, 2005), but the detection of specific phytoplankton species or functional groupings using multispectral sensors has been challenging due to lack of sufficient spectral resolution to enable distinction (Gordon et al., 2001; Nair et al., 2008). Since marine environments are complex ecosystems typically supporting a diverse community of phytoplankton species, the link between biodiversity, ecosystem structure, and ecological function is unresolved in current ocean color remote sensing science. It was in part to address this knowledge gap that NASA conceived of the Plankton, Aerosol, Cloud, ocean Ecosystem (PACE) mission. Onboard the PACE satellite, to be launched in 2022, the proposed hyperspectral Ocean Color Instrument (OCI) is being developed to retrieve marine reflectance with a continuous spectral sampling of 5-nm resolution from the ultraviolet (UV) to the near infrared (NIR) (320 to $900 \mathrm{~nm}$ ) with six additional short wave infrared (SWIR) channels. Potential ocean color products from PACE will include phytoplankton functional types (PFTs), marine net primary productivity, and marine carbon stocks, in addition to atmospheric products such as aerosol and cloud properties ("Pre-Aerosol, Clouds, and ocean Ecosystem (PACE) Mission Science Definition Team Report," 2012; Werdell, 2016). Although the additional spectral bands of PACE/OCI are expected to significantly advance ocean color science, challenges arise for atmospheric correction (Gao et al., 2000, 2009). The AC process must estimate and remove the atmospheric path radiance contribution due to the Rayleigh scattering by air molecules and scattering by aerosols from the measured top-of-atmosphere (TOA) radiance, compensate for the absorption by atmospheric gases, and correct for reflection and refraction of the air-sea interface. The residual signal is attributed to the light upwelling from beneath the ocean surface, and is typically $<15 \%$ of the TOA radiance, depending on the spectral range and ocean brightness. This water-leaving signal is 
then used to derive ocean color products assuming that an accurate atmospheric correction was applied (Ahmad et al., 2010; Gordon and Wang, 1994a). Multispectral ocean color missions typically avoid light detection at the spectral regions that are most affected by absorbing gases, especially water vapor which is highly variable spatially and temporally. Current ocean color atmospheric correction algorithms compensate mainly for ozone $\left(\mathrm{O}_{3}\right)$ and nitrogen dioxide $\left(\mathrm{NO}_{2}\right)$, which absorb light in broad spectral bands from the UV and throughout the visible spectral range (Ahmad et al., 2007). Spectral bands in the red and NIR (> $600 \mathrm{~nm}$ ) are specifically located to avoid water vapor absorption features that would otherwise complicate the derived correction for aerosol scattering and contaminate the derived water-leaving signal (Gordon and Wang, 1994a). To make full use of the additional spectral bands of hyperspectral instruments for ocean color, the effect of water vapor must be estimated and corrected. The complexity of the atmospheric water vapor profile, the spectrally variable nature of the absorption features, and the spatial heterogeneity of the water vapor concentration are factors that contribute to this challenge (Gao et al., 2000, 2009). Meanwhile, other absorbing gases, discussed in more details in section 2.2 , are either typically immutable and homogenous or their variability is well quantified based on climatological models or ancillary sources (Dee et al., 2011; Derber et al., 1991; Kanamitsu et al., 2002). In this work, we provide a hyperspectral remote sensing application, including AC and ocean color retrieval, based on the Hyperspectral Imager for Coastal Ocean (HICO). HICO (Table 1) is a hyperspectral imaging radiometer that operated onboard the international space station (ISS) from 2009 to 2014, capturing over 10,000 scenes over the globe (Corson et al., 2008, 2010; Korwan et al., 2009a; Lucke et al., 2011). HICO measured light with a spectral coverage from $353 \mathrm{~nm}$ to $1080 \mathrm{~nm}$ with a $5.7 \mathrm{~nm}$ spectral resolution. It has a pointing capability in the cross-track direction. At the nadir looking direction, the spatial resolution is $90 \mathrm{~m}$. HICO collected one scene per orbit of size 50 x $200 \mathrm{~km}$ that was scheduled weekly by the science team, with scenes mostly collected over coastal regions to derive products such as water clarity, benthic types, and bathymetry. HICO provided adequate radiometric performance to support ocean color applications in these coastal regions, where high concentrations of phytoplankton and suspended sediments result in strong water-leaving radiance in the visible regime, but scenes collected over darker, open ocean regions suffer from the relatively low signal to noise ratio (SNR), especially in the green to NIR regime (Korwan et al., 2009a; Lucke et al., 2011).

The work presented here will provide a detailed description of a hyperspectral atmospheric correction algorithm that combines the established capabilities of NASA's standard AC approach mainly for aerosols and Rayleigh scattering (L2GEN), currently distributed in SeaDAS ("SeaWiFS Data Analysis System (SeaDAS)," 2017), with the absorbing gas corrections found in ATmospheric REMoval code (ATREM), discussed in details in section 2.2 (Gao et al., 1993b). This enhanced version of L2GEN extends the multispectral Rayleigh/aerosol correction heritage approach (Ahmad et al., 2010; Gordon and Wang, 1994a) to the 
Table 1: HICO sensor and data characteristics.

\begin{tabular}{ll}
\hline \hline Platform & International Space Station (ISS) \\
Operation lifetime & $2009-2014$ \\
Orbit repeat time/period & 3 days $/ 90$ minutes \\
Scene size $(\mathrm{km})$ & $50 \times 200$ \\
Pixel size $(\mathrm{m})$ & $\sim 100$ \\
Wavelength $(\mathrm{nm})$ & $353-1080(128$ bands $)$ \\
Spectral resolution $(\mathrm{nm})$ & 5.7 \\
Spectral FWHM (nm) & $10(\leq 745 \mathrm{~nm}), 20(>745 \mathrm{~nm})$ \\
Sensor type & Offner Spectrometer \\
Signal-to-noise ratio (SNR) & $>200: 1$ assuming $5 \%$ surface albedo \\
Polarization sensitivity & $<5 \%$ \\
\hline
\end{tabular}

hyperspectral domain. The novelty of this work is that we have implemented and assessed an operationally viable algorithm for hyperspectral ocean color retrieval, that follows the well-established, well validated, heritage approach used by NASA for all global OC sensors. Water vapor correction is a significant addition to that heritage process, and necessary for meaningful OC retrieval in some spectral regions. The most important improvement related to HICO specifically is that HICO's AC processing has always been dependent on in-situ aerosol observations (such as aerosol optical depth, and assumed model). Meanwhile, in this work, we provide the community with atmospherically corrected data that is not limited by in-situ observation. The AC for HICO is completely automated such that the correction is inferred from HICO measurements itself as opposed to in-situ measurements. The general improvement is that this work shows the first operational hyperspectral AC and water-leaving reflectance retrieval of ocean color sensors. The operational algorithm can be the backbone and a starting point for the anticipated PACE mission. We also provide the space-borne hyperspectral data for the community to better understand the complication of hyperspectral remote sensing of ocean color and develop appropriate algorithms for such capabilities. We also present a system-level vicarious calibration to improve the radiometric stability of the HICO sensor and minimize bias in the atmospheric correction process (Franz et al., 2007). To assess the performance of the resulting water-leaving radiance retrievals, match-ups to in-situ radiometry from SeaBASS and AERONET-OC are presented and assessed. Finally, we show some case study results of ocean color retrievals over coastal regions in the Chesapeake Bay and the Gulf of Mexico and compare them with co-incident MODISA retrievals.

\section{Approach}

\subsection{Atmospheric correction}

The L2GEN (L2 generator), within the SeaDAS software package, is the multi-sensor Level-1 to Level-2 processing code developed and maintained by NASA's Ocean Biology Processing Group (OBPG) that is capable of retrieving ocean color products from TOA radiances for a host of multispectral sensors. L2GEN 
supports multiple atmospheric correction methods and variations that can be applied to a variety of ocean color sensors (Ahmad et al., 2010; Bailey et al., 2010; Gordon and Wang, 1994a; Ruddick et al., 2000; Wang et al., 2009). NASA's heritage atmospheric correction approach assumes the additive property of different contributing components in the atmosphere-ocean (AO) system to the top of atmosphere radiance, Lt, which can be approximated as:

$$
L_{t}(\lambda)=\left(L_{r}(\lambda)+L_{a}(\lambda)+L_{r a}(\lambda)+t(\lambda) L_{f}(\lambda)+T(\lambda) L_{g}(\lambda)+t(\lambda) L_{w}(\lambda)\right) \times T_{g}(\lambda)
$$

where $\lambda$ is a sensor spectral band wavelength, $L_{r}(\lambda)$ is the radiance due to multiple scattering by air molecules in the absence of aerosols (i.e. Rayleigh scattering), $L_{a}(\lambda)$ is multiple scattering by aerosols in the absence of Rayleigh, and $L_{r a}(\lambda)$ is the radiance contribution due to Rayleigh-aerosol interactions. $T_{g}(\lambda)$, $T(\lambda)$ and $t(\lambda)$ are the gaseous transmittance and the direct and diffuse transmittance, respectively, from Sun to surface to the sensor. $L_{g}(\lambda)$ is the surface glint in the specular direction and $L_{f}(\lambda)$ is the contribution from whitecaps and foam on the surface that is transmitted to the sensor field of view. $L_{w}(\lambda)$ is the water-leaving radiance that is to be retrieved after the atmospheric correction process, by removing and compensating for all other components in Eq. (1). Pre-computed look-up tables (LUT) generated using vector radiative transfer (VRT) simulations are used to model the Rayleigh and aerosol contributions (Ahmad et al., 2010; Ahmad and Fraser, 1982). The Rayleigh scattering term, which is the dominant contribution over the visible regime, is simulated for a wide range of solar and viewing geometries (Ahmad et al., 2010). The hyperspectral optical properties used in the VRT simulations, such as the extraterrestrial solar irradiance, Rayleigh optical thickness, and the depolarization factors, were optically weighted for the sensor-specific spectral response function (Bodhaine et al., 1999; Thuillier et al., 2003). The hyperspectral Rayleigh LUTs are also a function of wind speed, to account for secondary AO coupling effects (i.e., the multiple scattered light interactions between the atmosphere and the ocean surface), and the inferred Rayleigh scattering coefficient is adjusted for surface pressure and terrain height (to support retrievals over inland water masses) (Ahmad and Fraser, 1982; Bodhaine et al., 1999). Glint and whitecap radiance contributions are modeled based on ancillary wind speed and observing geometry (Cox and Munk, 1954; Frouin et al., 1996; Gordon and Wang, 1994b; Koepke, 1984). The aerosol radiometric contribution is estimated using the method of Gordon and Wang, 1994 (Gordon and Wang, 1994) with aerosol models developed by Ahmad et al., 2010 (Ahmad et al., 2010), and coupled with an iterative bio-optical model to separate the scattering contributions from aerosols and watercolumn constituents in turbid (high-scattering) waters (Bailey et al., 2010). The Gordon and Wang approach uses a pair of bands in the NIR or SWIR to derive the spectral slope in measured aerosol reflectance, which is then compared to the pre-computed aerosol LUTs representing a range of aerosol models (varying aerosol 
optical properties). The method finds the closest set of aerosol models to the observation, and a weighting scheme is then applied to the models that enables the radiance contribution to be extrapolated to the visible part of the spectrum. Thus, the aerosol term and the Rayleigh-aerosol interaction contributions can be estimated and removed from all spectral bands. The pair of bands in the NIR or SWIR should be sensitive to variations in aerosol type and concentration (optical thickness) and avoid contamination from gaseous absorption, especially water vapor. Spectral calibration problems in HICO, such as second-order diffraction effects on the optical diffraction grating system, contribute to severely degraded radiometric performance in the wavelength range $>800 \mathrm{~nm}$, rendering this part of the spectrum unreliable for determination of aerosol contribution (Corson et al., 2008; Gao et al., 2012; Gao and Li, 2010; Korwan et al., 2009b). The remaining spectral windows in the red/NIR part of the spectrum are few, due to contamination by water vapor and oxygen absorption. To minimize these influences, the spectral band pair at $747 \mathrm{~nm}$ and $787 \mathrm{~nm}$ was selected for the aerosol correction. In bright waters, those two bands will be impacted by the non-negligible water-leaving radiance, therefore it is important to apply the NIR correction algorithm (Bailey et al., 2010). Unfortunately, even for these carefully selected spectral bands, the $787 \mathrm{~nm}$ channel must still be corrected for contamination by oxygen. Due to the application of spectral smoothing in the calibration processing of HICO, the effective spectral bandwidth for wavelengths $>745 \mathrm{~nm}$ is $20 \mathrm{~nm}$, so the $787 \mathrm{~nm}$ is affected by the Oxygen A-band (759-770 nm) (Gao et al., 2012). Oxygen also absorbs light at the Oxygen B-band (688 $\mathrm{nm}$ ) and slightly at $\sim 630 \mathrm{~nm}$. Water vapor slightly absorbs the visible light at selective wavelengths and is a dominant absorber in the SWIR spectral range, with some notably strong absorption features in the red part of the spectrum where we wish to retrieve the water-leaving radiance or its normalized "remote sensing" reflectance, $R_{r s}(\lambda)$ :

$$
R_{r s}(\lambda)=\frac{f}{Q}(\lambda) \times L_{w}(\lambda) / E_{d}(\lambda)
$$

where $E_{d}(\lambda)$ is the downwelling solar irradiance calculated as:

$$
E_{d}(\lambda)=T_{g 0}(\lambda) \times t_{0}(\lambda) \times F_{0}(\lambda) \times f_{0}(\lambda) \times \cos \theta_{0}
$$

$T_{g 0}(\lambda)$ and $t_{0}(\lambda)$ are the gaseous transmittances and transmittances of solar irradiance from Sun to surface, respectively. $F_{0}(\lambda)$ is the mean extraterrestrial solar irradiance, $f_{0}(\lambda)$ is the Earth-Sun distance correction for the time of the observation, and $\theta_{0}$ is the solar zenith angle. In Eq. $(2), \frac{f}{Q}(\lambda)$ is the bidirectional reflectance correction factor to account for the inhomogeneity of scattered light below the ocean surface and the effects of transmittance through the air-sea interface (Morel et al., 2002).

It is particularly important to retrieve accurate $R_{r s}(\lambda)$ across the visible spectral range when applying 
results to algorithms that utilize the spectral shape or spectral derivatives to derive bio-optical properties such as phytoplankton functional types ("IOCCG (2014). Phytoplankton Functional Types from Space," 2014; Lubac et al., 2008; Ryan et al., 2014). Residual spectral features in $R_{r s}(\lambda)$ resulting from inaccurate compensation for water vapor absorption will degrade our ability to retrieve these advanced bio-optical properties.

\subsection{Absorbing gases correction}

The gaseous absorption term, $T_{g}(\lambda)$, in Eq. (1) is calculated from the ATREM program (Gao and Davis, 1997), which calculates the Line-by-Line (LBL) transmittance of seven gases: water vapor $\left(\mathrm{H}_{2} \mathrm{O}\right)$, carbon dioxide $\left(\mathrm{CO}_{2}\right)$, ozone $\left(\mathrm{O}_{3}\right)$, nitrous oxide $\left(\mathrm{N}_{2} \mathrm{O}\right)$, carbon monoxide $(\mathrm{CO})$, methane $\left(\mathrm{CH}_{4}\right)$, and oxygen $\left(\mathrm{O}_{2}\right)$ for the spectral region 400-3000 $\mathrm{nm}$. The ATREM algorithm was integrated into L2GEN to provide hyperspectral compensation of the water vapor absorption for the atmospheric correction process. Concentrations of other gases such as $\mathrm{O}_{2}, \mathrm{O}_{3}$, and $\mathrm{NO}_{2}$, were determined using ancillary sources (Dee et al., 2011; Derber et al., 1991; Kanamitsu et al., 2002). The ancillary information is ingested into L2GEN to calculate the transmittance along the two-way path from the Sun to the surface to the sensor. In L2GEN, ATREM calculates the transmittance using the HITRAN 2012 database at $0.05 \mathrm{~cm}^{-1}$ wavenumber spectral resolution, which is down-sampled to a sensor spectral resolution. ATREM has the capability to estimate the column water vapor amount (CWV) (given the water vapor volume mixing ratio (VMR) profile) and correct for the water vapor absorption along the radiant path. It does so by using a 3-band ratio technique utilizing two atmospheric window channels around one absorbing water vapor band. The trough in the TOA reflectance at the water vapor band relative to the two window bands is correlated to the water vapor amount along the path that the light traveled. The 3-band ratio algorithm assumes that the surface reflectance is spectrally monotonic and that any surface spectral features within the spectral windows can lead to erroneous correction for water vapor transmittance losses. Fortunately, ocean reflectance is generally monotonic in the red/NIR part of the spectrum, except in extreme bloom conditions and floating vegetation (i.e. Cyanobacteria blooms where there is a peak in reflectance around $710 \mathrm{~nm}$ ) (Kudela et al., 2015).

For HICO, the spectral range contains three prominent absorbing water vapor bands, 725,825 , and 940 $\mathrm{nm}$. Due to the radiometric calibration issues, the 825 and $940 \mathrm{~nm}$ bands are unavailable for determination of water vapor correction with $\mathrm{HICO}$, thus the $725-\mathrm{nm}$ band is used to estimate the water vapor transmittance along the path. The two window channels are selected to be 705 and $740 \mathrm{~nm}$ since they are minimally impacted by other gases absorption (i.e., oxygen), and spectrally close, thus reducing the uncertainties associated with a non-monotonic surface reflectance (Gao et al., 1993a). The water vapor amount estimated from these 3-bands is used to calculate the spectral transmittance along the path, which is combined with 
the derived transmittance effects of the other gases to form $T_{g}(\lambda)$ of Eq. (1). A detailed discussion about band selection is in section 2.4. The transmittance of $\mathrm{NO}_{2}, \mathrm{O}_{3}, \mathrm{H}_{2} \mathrm{O}, \mathrm{O}_{2}$ absorbing gases, and the total transmittance, modulated by HICO's spectral response function, are shown in Fig. 1.



Figure 1: The gases transmittance for a tropical atmosphere for HICO channels with ozone concentration of 277 DU and column water vapor of $3.3 \mathrm{~cm}$.

The LBL calculations for every pixel in the scene (i.e. varying Sun and viewing geometry) are computationally intensive. A number of methods have been developed to improve the computational efficiency of the LBL approach (Gao and Kaufman, 2003). In this work, we adapted the k-distribution method, which involves the grouping by strength of the gas absorption coefficients within a frequency or wavelength interval (Kato et al., 1999; Lacis and Oinas, 1991). The interval is selected either based on the sensor spectral bandwidth or some set of subintervals with far fewer points to represent the spectral absorption relative to the LBL computations. A carefully selected binning or interpolation technique is needed to accurately represent the k-bins. Since ranking the LBL absorption coefficients in every subinterval will provide a smooth cumulative frequency distribution function $(\mathrm{CDF})$, a 7-point interpolation scheme allowed us to model the coefficient accurately, thereby reducing thousands of points in every interval to only 7 . The transmittance for every interval is calculated as follows:

$$
T\left(B_{i}\right)=\frac{1}{\nu_{2}-\nu_{1}} \int_{\nu_{1}}^{\nu_{2}} e^{-K(g) \times \rho} d g
$$

and

$$
K(g)=\int_{-\infty}^{\nu_{2}} a\left(B_{i}\right) d g
$$

The k-binned absorption coefficients are a function of the bins $\mathrm{g}$, where $K(g)$ is calculated from the CDF 
of the LBL absorption coefficient, $a\left(B_{i}\right)$, for every band or interval $B_{i} . \rho$ is the integrated absorbing gas density along the path in the atmosphere. The transmittance per band, $T\left(B_{i}\right)$ is then calculated using the Beer-Lambert law for each of the 19 layers of the atmosphere, and the multiplicity property is applied. To demonstrate this mathematical transformation, we show in Fig. 2 the LBL absorption coefficients within the $725 \mathrm{~nm}$ water vapor band with $5.7 \mathrm{~nm}$ window, the smooth $\mathrm{k}$-distributed absorption coefficients, and the interpolated bins.


Figure 2: The LBL water vapor transmittance and the k-distribution coefficients at $725 \mathrm{~nm}$.

Based on this approach, the water vapor transmittance can be calculated 3 orders of magnitude faster than the LBL calculations. Also, this approach gives the flexibility to have dual capabilities of the fast kdistribution and slow LBL approach to possibly assess spectral shift calibration using absorbing-gas features (Gao et al., 2012). The k-distribution approach was implemented into L2GEN so that changes in the spectral response function or the band center of detectors will be adjusted instantaneously in the program without the need to recalculate the binning. Although the k-distribution method is an exact solution to dramatically reduce the computation, the approximated 7-point interpolation and the limits of subintervals per band can lead to some errors. Based on our analysis, the error in the water vapor transmittance can reach $1.5 \%$ at 725 $\mathrm{nm}$ in the worst-case scenario, when the amount of the column water vapor is higher than $4 \mathrm{~cm}$. Typically, in open ocean conditions, the column water vapor is between 0.5 and $3 \mathrm{~cm}$, thus the error in water vapor transmittance is less than 1\% (Gao and Kaufman, 2003). In addition, since the spectral sensitivity of HICO bands are assumed to be Gaussian distributed (consistent with the calibration algorithm), the tails of the distribution will not be represented properly in the k-bin. These issues are sensor specific as long as the band filter distribution remains the same. By performing LBL calculations for a small subset of a given scene (typically 1 pixel), normalization coefficients are derived to remove any marginal errors introduced from the k-distribution method. In that way, the computational time is small, while the error relative to the full LBL 
calculations is reduced to $0.1 \%$.

\subsection{Absorption-scattering coupling effects in the atmosphere}

The transmittance of diffused light, in Eq. (1) and (2), through the atmosphere does not account for the coupling between the gases absorption and aerosol + Rayleigh scattering. With increasing scattering in the atmosphere, the multiple-scattered radiance is increasingly affected by the absorbing gases along the path. Therefore, the treatment of gaseous absorption as predominantly governed by Beer-Lambert law is not accurate, especially when the atmospheric signal is dominated by highly-absorbing gases features such as the Oxygen A-band and strong water vapor absorption regions. Since we are ignoring these coupling effects, it is important to assess the uncertainty associated with the atmospheric correction process. Fig. 3 shows the TOA reflectance, $L_{\mathrm{t}} / F_{0}$, for an atmosphere-ocean coupled system for two cases: one includes water vapor absorption in the atmosphere, and the other does not, where $L_{\mathrm{t}}$ and $F_{0}$ are the upwelling TOA radiance at nadir and the solar extraterrestrial irradiance, respectively. The solar zenith angle of $10^{\circ}$ is used. When including aerosol scattering, an exact and efficient vector radiative transfer model is employed for the sensitivity study to simulate the TOA reflectance between $600 \mathrm{~nm}$ and $800 \mathrm{~nm}$, which is based on the successive order of scattering method (Zhai et al., 2009, 2010, 2015, 2017). The atmosphere is assumed to be a mixture of molecules and aerosols. The molecular scattering properties are determined by the Rayleigh scattering matrix and the optical depth is calculated from the method in Tomasi et al., 2005 (Tomasi et al., 2005). The aerosol scattering matrix is determined by the aerosol model developed for ocean color atmospheric correction, with $50 \%$ of fine mode volume fraction and $80 \%$ of relative humidity (Ahmad et al., 2010). The aerosol optical depth at $550 \mathrm{~nm}$ is 0.2 . The aerosol vertical distribution is based on the average dust case in Braslau et al., 1973 (Braslau and Dave, 1973). The ocean surface is a rough dielectric surface with surface slope distribution determined by the parameterization of Cox and Munk (1954) with the wind speed of $6 \mathrm{~m} / \mathrm{s}$ (Cox and Munk, 1954). There is no ocean water body in this case. For the case with water vapor absorption, the water vapor absorption coefficient is obtained from the HITRAN 2012 database (Rothman et al., 2013). The water vapor volume mixing ratio has a realistic vertical profile that is $2.5 \%$ at the surface, decreasing to $1 \%$ at $2.5 \mathrm{~km}$ and almost zero at $10 \mathrm{~km}$, so that the top layers of the atmosphere do not have any water vapor absorption. For the case without water vapor absorption, the atmosphere is assumed to be conservative with the same scattering properties as the case with water vapor absorption. In Fig. 3 (a), the simulations were performed with fine spectral resolution and then averaged to an assumed $\sim 2 \mathrm{~nm}$ square band. The line of "Reconstructed" is calculated by using $L_{\mathrm{t}} / F_{0}$ for the case with no water vapor absorption, multiplied the two-way gas transmittance due to water vapor in the atmosphere, which estimates the TOA radiance field by ignoring absorption and scattering interaction. Fig. 3 (b) is the 
percentage difference between the case with water vapor absorption and the line of "Reconstructed", which is a representation of the absorption and scattering decoupling error.


Figure 3: (a) is the TOA remote sensing reflectance, $L_{\mathrm{t}} / F_{0}$, from 600 to $800 \mathrm{~nm}$ simulated for three scenarios: no water vapor absorption in green dashed line, in the presence of water vapor absorption coupled with atmospheric scattering in the RT simulations in black solid line, and the reconstructed TOA reflectance calculated from the no water vapor absorption reflectance multiplied by the two-way gas transmittance due to water vapor in the atmosphere in red dashed line. (b) is the absorption-scattering decoupling percentage error.

Fig. 3 (a) and (b) shows that the decoupling error is large for spectral regions with large water vapor absorption. The decoupling error is almost everywhere negative, which means that the "Reconstructed" line is smaller than the exact radiative transfer simulation with water vapor absorption included. This is because the water vapor profile is concentrated at the bottom of the atmosphere. Many photons in solar light are scattered back to space at the top layers of the atmosphere, which does not possess any water vapor absorption. These photons do not penetrate to the bottom of the atmosphere, and thus do not suffer the water vapor absorption at the bottom of the atmosphere. In the absorption-scattering decoupling approximation, no discrimination is used for photons scattered at different layers of the atmosphere, which is why the decoupling approach underestimates the TOA reflectance. This effect is stronger for spectral regions with stronger water vapor absorption. Fig. 3 (b) shows that this error ranges from $0 \%$ to $10 \%$ for the case studied, which has $2 \mathrm{~nm}$ spectral resolution. This decoupling error is highly dependent on the spectral resolution, with larger error expected for finer spectral resolution. Decoupling errors can also be significant for other remote sensing applications. For example, the aerosol scale height can be significantly underestimated over dark surfaces when utilizing the Oxygen A-band (Dubuisson et al., 2001). To augment the problem, Dubuisson et al., 2001 suggest to derive a correction factor, based on extensive RT simulations for varying aerosol optical thickness and geometries, reducing the algorithm uncertainties by an order of magnitude (Dubuisson et al., 2001). The importance of a correction method was first reported in Frouin et al., 1990, to improve the estimation of CWV over dark ocean surfaces (Frouin et al., 1990). This method was 
then formulated in Dubuisson et al, 2004, where a correction factor was derived as a function of geometry, aerosol optical thickness, and aerosol scale height that reduces the retrieval uncertainties of CWV (Dubuisson et al., 2004). For ocean color, decoupling correction is also important for the detection of phytoplankton fluorescence near $685 \mathrm{~nm}$, where both the Oxygen B-band and water vapor absorb. Decoupling correction methods will be developed and implemented in a future SeaDAS (L2GEN) release.

\subsection{Selection of water vapor bands for $\mathrm{HICO}$}

While our primary goal is to retrieve the gas transmittance for atmospheric correction, with additional assumptions we can also retrieve the total column water vapor that is of interest for atmospheric science. Using the modified L2GEN, the column water vapor in the atmosphere can be retrieved for a given water vapor volume mixing ratio (VMR) profile within the atmospheric column. The sensitivity of unknown column water vapor VMR profile, surface reflectance, or the presence of thin clouds can introduce more than $10 \%$ error in the retrieval of column water vapor (Gao et al., 1993a; Gao and Kaufman, 2003; Kaufman and Gao, 1992). The uncertainties in removing the spectral absorption features from the TOA radiance, however, is less significant (Gao et al., 2000). To understand the algorithm errors related to HICO's band selection for the retrieval and correction of water vapor, we utilized vector radiative transfer simulation program, MYSTIC, which is a Monte Carlo based RT code, that is computationally efficient during the absence of scattering aerosols (i.e. Rayleigh only atmosphere), available through the open source RT library called Libradtran (Emde et al., 2016; Mayer, 2009). Furthermore, since the MYSTIC code is an open source and well-benchmarked throughout the atmospheric community, we were attracted towards utilizing MYSTIC over the SOS code for the case of high spectral resolution and large number of water vapor simulation cases. Meanwhile, a comprehensive benchmark study of the SOS code, including an efficient water vapor calculations is currently in progress and has not been published. On the other hand, the SOS case study in section 2.3, which is more efficient in handling scattering aerosols, has been compared to the MYSTIC code, yielding similar results. The MYSTIC code was used to simulate the polarized TOA radiance for a simple Rayleigh atmosphere and absorbing flat ocean, at a very high wavenumber spectral resolution of $1 \mathrm{~cm}^{-1}$ $(\sim 0.01 \mathrm{~nm}$ in VIS). Water vapor is assumed to be the only absorber in the atmosphere, which is coupled with the scattering in the VRT simulations. The simulation runs were calculated for $0.3,0.5,0.7,1,1.3$, $1.5,1.7,2,2.3,2.5,2.7$, and $3 \mathrm{~cm}$ column water vapor at geometries permuted from $10^{\circ}$ to $50^{\circ}$ solar and viewing zenith angle with $10^{\circ}$ step, while the relative azimuth was fixed to be $90^{\circ}$ composing a total of 300 cases. The water vapor profile was assumed to be the US standard 1976 and the water vapor absorption coefficients were obtained from the HITRAN 2012 database (Anderson et al., 1986; Rothman et al., 2013) . The high spectral resolution TOA radiance was then convolved with HICO's spectral response function. 
Fig. 4 (a) shows, as an example, the simulated TOA reflectance at $10^{\circ}$ solar angle, $30^{\circ}$ sensor angle, and $90^{\circ}$ relative azimuth angle.


Figure 4: (a) Top of the atmosphere reflectance at $10^{\circ}$ solar angle, $30^{\circ}$ sensor angle, and $90^{\circ}$ relative azimuth angle for 12 different column water vapor values: $0.3,0.5,0.7,1,1.3,1.5,1.7,2,2.3,2.5,2.7$, and $3 \mathrm{~cm}$ simulated for HICO. (b) The corresponding water vapor transmittance along the radiance path for 12 different column water vapor values. (c) is an inset of the transmittance for wavelengths range from 700 to $1000 \mathrm{~nm}$.

The TOA reflectance has features imposed by the water vapor absorption along the radiance path. The strongest water vapor features are in the 725, 825, and $940 \mathrm{~nm}$ regions as shown in Fig. 4 (b). To compensate for these features, the water vapor transmittance is calculated from L2GEN and the TOA reflectance is corrected by dividing it by the gas transmittance along the path.



Figure 5: Scatter plot between the assumed CWV in the VRT simulations and the retrieved CWV using L2GEN using a pair of water vapor channels at 820 and $940 \mathrm{~nm}$ (red circles), 720 and $820 \mathrm{~nm}$ (blue circles), and $720 \mathrm{~nm}$ only (black circle). The error bar is the standard deviation due to changes in solar and viewing geometries.

Fig. 5 shows the scatter plot between the assumed CWV in the VRT simulations and the retrieval of CWV by L2GEN. In this analysis, we used three modes of retrieval. The first is using the average CWV 
retrieval using the strongly absorbing $940 \mathrm{~nm}$ band and the less sensitive $820 \mathrm{~nm}$ band shown in blue circles, with the error bar of 1 standard deviation due to changes in the simulated geometries. With this combination, the CWV retrieval shows a strong underestimation at higher water vapor concentrations. This is due to the combination of a weak ocean signal (in that case ocean surface reflectance) and a strongly absorbing 940 -nm water vapor feature that leads to loss of sensitivity to further increases in CWV. The retrieval for CWV less than $1 \mathrm{~cm}$, however, shows good performance suggesting that the 940-nm channel can be well utilized to detect and retrieve small amounts of water vapor in the atmosphere, while its sensitivity saturates for larger than $1 \mathrm{~cm}$ CWV. The second mode of CWV retrieval shown in green circles, using an average of CWV retrievals at both 720 and $820 \mathrm{~nm}$, shows very good performance along the whole dynamic range of CWV. Although the retrieval shows a slight bias at small CWV values, the impact of erroneous (biased) CWV at low values is less significant on the $R_{r s}$ of the ocean, especially at weakly absorbing bands in the visible range of the spectrum. The third mode of CWV retrievals using $720 \mathrm{~nm}$ only, shows also a good retrieval along the whole dynamic range. Retrievals at low CWV values show less bias compared to the combination of 720 and $820 \mathrm{~nm}$, while there is a stronger bias at high CWV values. The absolute average percent error (AAPD) is $19 \%, 8.5 \%$, and $9 \%$ for retrievals using 820 and $940 \mathrm{~nm}, 720$ and $820 \mathrm{~nm}$, and 720 nm only, respectively. In Gao and Kaufman, 2003, their CWV retrieval using MODIS showed a systematic bias relative to both a ground-based sunphotometers (AERONET) observations and a smaller bias to a ground-based, upward looking microwave radiometer (Gao and Kaufman 2003). In the latter case, the error in CWV retrieval was less than $10 \%$ which corroborates with the analysis shown here, except in the 820 and 940 nm combination, which is not ideal for a wide dynamic range of retrievals. Based on the analysis presented here, it is therefore recommended to use either 720 or $820 \mathrm{~nm}$ or both for the atmospheric correction of water vapor over oceans. For HICO, the $720-\mathrm{nm}$ band is used alone, due to the increased uncertainty for spectral bands above 800 nm.

\section{Radiometric corrections for $\mathrm{HICO}$}

In addition to the known calibration problems with HICO such as second-order optically diffracted stray light effects from the grating system in the NIR-SWIR, smile effects, thermal instability, electronic smear and low SNR values, spectral band shifts can also lead to poor performance for the correction of gases with strong spectral features, such as oxygen and water vapor. To further reduce the impact of sensor calibration errors, a vicarious calibration was developed and applied to HICO. 


\subsection{Center Wavelength Shift}

Since the post-launch spectral calibration of HICO is not well tracked, due to the lack of an onboard calibration system, and in order to understand the impact of spectral miscalibration in bands center, an error analysis was conducted to evaluate the possible error induced in the gas absorption correction algorithm. The spectral miscalibration will predominantly impact the correction for gases with sharp spectral features, such as oxygen and water vapor. Fig. 6 shows the error in water vapor transmittance at three prominent water vapor features in the VIS/NIR range at 590,720, and $820 \mathrm{~nm}$. This theoretical analysis assumes $5 \mathrm{~nm}$ square bands, and it shows the error in the water vapor transmittance of LBL calculations and the un-interpolated k-distribution calculations (where they have $<0.1 \%$ error in transmittance without any miscalibration) with shifted from the band centers. It is shown in the figure that the error can be as high as $20 \%$ for $2 \mathrm{~nm}$ band center shift at $720 \mathrm{~nm}$. The error is also a function of the column water vapor, where it is positively correlated.


Figure 6: The error in water vapor transmittance at 590, 720, and $820 \mathrm{~nm}$ as a function of the column water vapor induced by a spectral band center shift.

This analysis shows the importance of evaluating band center shifts and the error associated with it for gas corrections. For example, Gao et al., 2012 showed that HICO suffered a band center shift immediately post-launch (Gao et al., 2012). The initial spectral shift was $-1.72 \mathrm{~nm}$ that stabilized to $-0.9 \mathrm{~nm}$ shift. In the analysis by Gao et al., 2012, a spectral matching technique was used to evaluate the spectral shift based on the known oxygen feature at $765 \mathrm{~nm}$. The spectral matching technique of the transmittance was calculated using the LBL absorption coefficients which are necessary for evaluating sharp gases absorption features, as opposed to the pre-computed k-distribution coefficients for a predetermined set of band centers and bandwidths. Therefore, the k-distribution is required to be re-computed with the possibly shifted bands in order to have a proper gas correction, which is implemented in L2GEN. 


\subsection{Vicarious calibration}

The vicarious calibration of ocean color satellite-borne or airborne radiometers is a system-level calibration, wherein a set of spectral gains are derived that adjust the TOA radiances to minimize the differences between retrieved water-leaving radiances and high-quality in-situ water-leaving radiance measurements. Vicarious calibration is an integral part of ocean color remote sensing because the sensitivity of ocean color retrievals to radiometric or algorithmic bias is very high. Although HICO is an experimental hyperspectral instrument with known calibration stability issues, a vicarious calibration can significantly improve ocean color retrievals. In this paper, vicarious calibration is applied to HICO to minimize residual bias in $R_{r s}(\lambda)$ retrievals due to instrument calibration error and/or systematic algorithm error (Franz et al., 2007). All NASA-supported ocean color missions have used the Marine Optical BuoY (MOBY) near Lanai, Hawaii, which has been continuously operated by NOAA since 1996, as the in-situ calibration source for vicarious calibration (Clark et al., 1997). The approach involves two steps: 1) vicariously calibrate the pair of bands in the NIR (i.e. 747 and $787 \mathrm{~nm}$ ) used to estimate the aerosol contribution at the TOA and 2) vicariously calibrate the remaining bands at the MOBY site, using the atmospheric correction as calibrated in step 1. To calibrate HICO's NIR bands, the only 10 available scenes over the South Pacific Gyre (SPG) were used and the vicarious calibration was applied assuming zero water-leaving radiance in the NIR. The closest atmospheric aerosol models to the 80 -aerosol model suite, shown in table 2, estimated from the aerosols spectral slope from 443-869 nm (average Ångström) and relative humidity (RH), were taken from co-located, semi-co-incident MODISA aerosol model retrievals, after screening for clouds. When MODISA scenes are cloudy, the aerosol models for HICO scenes (Model Ångström) were assumed based on the ancillary relative humidity (RH) and climatological aerosol models of mostly coarse sea-salt particles as in Franz et al., 2007, shown in table 2.

The vicarious calibration of the NIR bands is challenged by low SNR. To improve the SNR, we performed an optimization analysis by spatially averaging the $\sim 100 \mathrm{~m}$ pixel to larger pixel sizes. The coefficient of variation $(C V=\sigma / \mu)$ for the Ångström coefficient, which is an indicator of aerosol type, was calculated for various binned pixel sizes (Fig. 7). $\sigma$ is the standard deviation and $\mu$ is the average of the Ångström coefficient of the entire image.Typically, over the SPG regions, aerosols are of oceanic type (i.e. sea salt aerosols), and since these remote regions are not impacted by anthropogenic effects, a spatial homogeneity in aerosol type is expected. In Fig. 7, the CV becomes smaller and reaches near-asymptotic beyond $1 \mathrm{~km}$ pixel size. Based on this analysis, a 1-km pixel resolution was selected for the vicarious calibration analysis.

Using the vicarious calibration process with the assumed aerosol models shown in Table 2, a pair of gains was derived with $1 \mathrm{~km}$ pixel size. The derived gain factors are 1.038 and 1 at 747 and $787 \mathrm{~nm}$, respectively. To vicariously calibrate the visible and other NIR bands, nearly $100 \mathrm{HICO}$ scenes were collected over the 
Table 2: Selected SPG scenes for NIR vicarious calibration

\begin{tabular}{|c|c|c|c|c|c|c|}
\hline $\begin{array}{c}\text { HICO } \\
\text { file name }\end{array}$ & Date & $\begin{array}{c}\text { Time } \\
\text { (UTC) }\end{array}$ & $\begin{array}{l}\text { Co-located MOIDSA } \\
\text { file name }\end{array}$ & $\begin{array}{c}\text { MODISA } \\
\text { average } \\
\text { Ångström }\end{array}$ & $\begin{array}{c}\text { Average } \\
\text { RH(\%) }\end{array}$ & $\begin{array}{c}\text { Model } \\
\text { Ångström } \\
\text { applied to } \\
\text { HICO }\end{array}$ \\
\hline H2010079203605 & $\begin{array}{l}2010- \\
02-01\end{array}$ & $02: 04$ & $\begin{array}{c}\text { A2010032014000 \& } \\
\text { A2010032014500 }\end{array}$ & cloudy & 72.91 & 0.6848 \\
\hline H2010122031458 & $\begin{array}{l}2010- \\
02-19\end{array}$ & 08:31 & A2010063010000 & cloudy & 76.67 & 0.7651 \\
\hline H2010157020639 & $\begin{array}{l}2010- \\
03-03\end{array}$ & $12: 21$ & A2010061011000 & 0.9028 & 78.68 & 0.8527 \\
\hline H2010162222953 & $\begin{array}{l}2010- \\
03-02\end{array}$ & $12: 23$ & A2010061223500 & cloudy & 77.85 & 0.7877 \\
\hline H2010216003529 & $\begin{array}{l}2010- \\
03-22\end{array}$ & 04:03 & A2010081235000 & 0.8264 & 75.53 & 0.8033 \\
\hline H2011099205338 & $\begin{array}{l}2011- \\
02-12\end{array}$ & 08:05 & A2011044013500 & cloudy & 73.42 & 0.7651 \\
\hline H2011231021638 & $\begin{array}{l}2011- \\
03-25\end{array}$ & $06: 22$ & A2011085013000 & cloudy & 73.10 & 0.7651 \\
\hline H2012103031211 & $\begin{array}{l}2012- \\
02-10\end{array}$ & $08: 31$ & A2012042011500 & cloudy & 75.61 & 0.7651 \\
\hline H2012151211730 & $\begin{array}{l}2012- \\
02-22\end{array}$ & $02: 12$ & A2012054014000 & cloudy & 71.52 & 0.6848 \\
\hline H2012227014530 & $\begin{array}{l}2012- \\
03-22\end{array}$ & $04: 14$ & A2012083011000 & cloudy & 71.51 & 0.6848 \\
\hline
\end{tabular}

MOBY site. After filtering for cloudy scenes, and limiting co-incidence of HICO's overpass with the in-situ measurement to $+/-3$ hours, 17 scenes were selected to perform the vicarious calibration. Fig. 8 shows the derived median and standard deviation of the hyperspectral gains (the full list of gain values is provided in the Appendix). Due to the calibration problems in the UV and NIR bands $>800 \mathrm{~nm}$, the gains were unstable (due to secondary diffracted light effects on the detector and lack of thermally stable system) and deviate dramatically from 1, while the average gains between $400-800 \mathrm{~nm}$ showed much better consistency, with values generally within $5 \%$ of unity. We have also made sure to examine the gain coefficients in the water vapor absorption spectral bands $<800 \mathrm{~nm}$, and we noticed that there are no or little water vapor features in the gain coefficients. We believe that the water vapor correction was done properly even before the vicarious calibrations as discussed in our theoretical analysis in section 2.4.

\section{Results and discussion}

The atmospheric correction algorithm and the gains derived from the vicarious calibration process were applied to the HICO observations to retrieve hyperspectral $R_{r s}$. As a verification of system performance, the approach was applied to all HICO scenes available over the MOBY site. In Fig. $9, R_{r s}$ derived from HICO after the atmospheric correction process, with and without applying the vicarious gain factors, are compared to MOBY's in-situ $R_{r s}$ optically integrated to HICO's spectral response function. Also shown is 



Figure 7: The CV and normalized CV of the Ångström coefficient for different pixel sizes for 10 HICO scenes collected at the SPG. The black vertical dashed line is at the $0.5 \mathrm{~km}$ aggregated pixel, while the black vertical solid line is at $1.1 \mathrm{~km}$ aggregated pixel.

co-incident $R_{r s}$ from MODISA, when available. It is clear that the $R_{r s}$ match-ups from HICO are improved after applying the vicarious calibrations, showing a good agreement with both in-situ MOBY and MODISA retrievals. HICO's $R_{r s}$ also does not contain any features from the absorbing gases (i.e., negative reflectance at the 720 -nm and 820 -nm water vapor bands), including at the water vapor bands, emphasizing that the gaseous compensation process is performing well.

The hyperspectral comparison of HICO and MOBY $R_{r s}$ is very good, except at wavelengths $>800 \mathrm{~nm}$ where the $R_{r s}$ deviates from the expected zero reflectance possibly due to the second order light contribution from the visible to the NIR and thermal instability, effects for which the vicarious calibration can only account for mean systematic bias impacts. The average root mean square error (RMSE) for calibrated HICO is 0.001, while before calibration it is 0.0024 . The improved NIR-band calibration, which that determines the aerosol contribution for the atmospheric correction, reduces the bias in the visible spectrum. Not shown here, radiometric performance of $\mathrm{HICO}$ in the UV wavelengths is also unreliable, but MOBY does not provide measurements in the UV to support vicarious calibration in that spectral range. Overall, the MODISA shows very good agreement in $R_{r s}$ with MOBY, as expected, since the vicarious calibration was performed at the same site. In addition, and unlike HICO, MODISA's calibration includes continuous monitoring and correction for temporal instabilities, using on-orbit calibration measurements of the Sun and the Moon (Franz et al., 2007; Meister et al., 2010; Sun et al., 2007; Xiong et al., 2010).

\subsection{Validation}

To provide a comprehensive validation of the atmospheric correction and vicarious calibration, we performed a matchup analysis between HICO $R_{r s}$ retrievals and NASA's SeaBASS and AERONET-OC global 


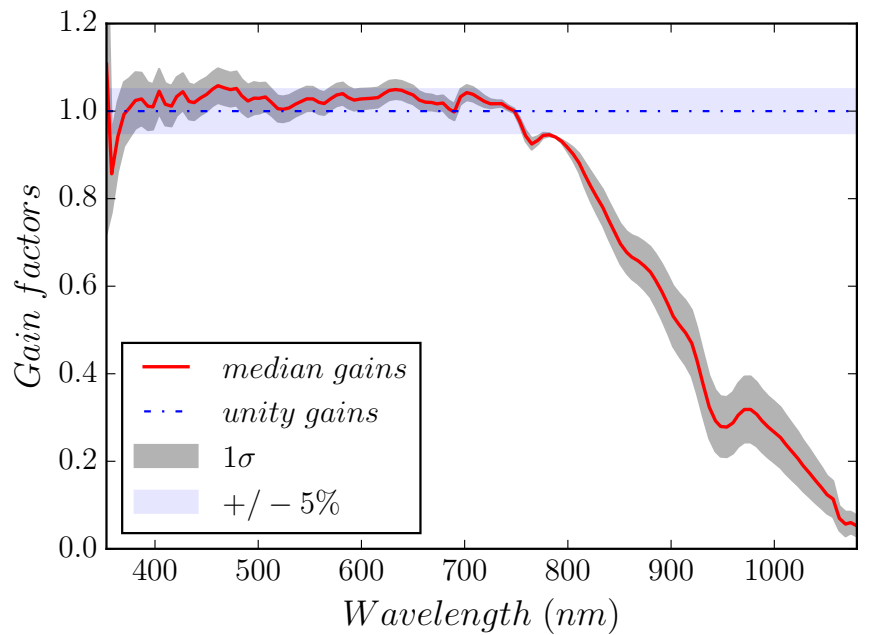

Figure 8: The hyperspectral median and standard deviation of gains derived from the vicarious calibration of 17 HICO scenes at MOBY.

in-situ dataset (Werdell et al., 2002; Zibordi et al., 2009). Hyperspectral match-ups were not possible because no successful match-ups were found within a $+/$ - 4-hour window of the data available, therefore we had to rely on creating match-ups with the more abundant multi-spectral data. Figure 10 shows the map of in-situ data points around the world. Most of the in-situ observation are located at AERONET-OC sites, since it's more feasible to target a fixed platform than a moving boat, especially when HICO acquired limited number of scenes and therefore, there are only very few SeaBASS data points.

The $R_{r s}$ match-ups were performed for 6 bands in the visible spectral range near 412, 443, 490, 547, 551, and $667 \mathrm{~nm}$. Fig. 11 shows the scatter plot comparison between HICO's $R_{r s}$ retrievals and in-situ $R_{r s}$ within a $+/-2$-hour window of the overpass. The figure shows the comparison with and without applying the vicarious gain factors. As expected, applying the gain factors shows an improvement in the match-ups, especially in the blue-green wavelengths, where they are more sensitive to atmospheric correction. The insitu data points represented measurements from various water conditions, from few clear water to mostly coastal regions, indicating that the vicarious calibration coefficients can be applied to globally acquired scenes. Table 3 shows a summary of the statistical indicators for the match-ups. Additionally, we performed a nonparametric hypothesis test using the Mann-Whitney U-test in order to evaluate the impact of the vicarious gains on the validation dataset. The $p$-values shown in table 3 indicate the significance of the vicarious gains for each band. The low $p$-values indicates the rejection of the null hypothesis (i.e. without vicarious gains), where the common rejection value is $p<0.05$. 













Figure 10: Location of global in-situ SeaBASS and AERONET-OC validation match-ups with HICO shown in red circles.


Figure 11: The scatter plot showing the multispectral $R_{r s}$ comparison between global in-situ SeaBASS and AERONET-OC dataset and HICO retrieval.

\subsection{Case studies}

HICO's capability to perform ocean color retrieval has been improved with hyperspectral atmospheric correction and vicarious calibration. The study case comparisons in this section between HICO and MODISA show the potential of HICO's ocean color applications spatially aggregated of TOA at 1-km pixels, but not down-sampled. Two locations were selected for comparison: 1) the Chesapeake Bay area, east coast of the United States; a highly complex and productive estuary with large anthropogenic influences on both the ocean and the atmosphere, and 2) the Gulf of Mexico coastal region off the northwest coast of Florida, United States, where phytoplankton blooms are frequent. In both cases, the atmospheric correction is challenging, as non-negligible ocean reflectance in the NIR can be significant. Fig. 12 (a) and (b) are the RGB true color image composites of the TOA radiance at 461, 553, and $639 \mathrm{~nm}$ for the Chesapeake Bay scene, and Gulf of Mexico scene, respectively. 
Table 3: A summary of statistical indicators to in-situ match-ups of HICO with in-situ $R_{r s}$ with and without vicarious calibration. The values in parenthesis are without vicarious calibration.

\begin{tabular}{ccccccc}
\hline Wavelength (nm) & $\mathbf{4 1 2}$ & $\mathbf{4 4 3}$ & $\mathbf{4 9 0}$ & $\mathbf{5 4 7}$ & $\mathbf{5 5 1}$ & $\mathbf{6 6 7}$ \\
\hline \hline $\mathbf{N}$ & 33 & 45 & 47 & 45 & 46 & 42 \\
\hline $\boldsymbol{R}^{\mathbf{2}}$ & 0.71 & 0.73 & 0.82 & 0.77 & 0.77 & 0.74 \\
& $(0.64)$ & $(0.67)$ & $(0.75)$ & $(0.72)$ & $(0.72)$ & $(0.74)$ \\
\hline RMSE & 0.0038 & 0.0027 & 0.0054 & 0.0011 & 0.0013 & 0.0004 \\
& $(0.019)$ & $(0.0112)$ & $(0.0104)$ & $(0.0091)$ & $(0.0084)$ & $(0.0023)$ \\
\hline slope & 0.95 & 1.20 & 1.06 & 1.03 & 1.03 & 1.14 \\
& $(0.98)$ & $(1.32)$ & $(1.15)$ & $(1.08)$ & $(1.08)$ & $(1.21)$ \\
\hline bias & -0.0004 & -0.0014 & -0.0013 & -0.0004 & -0.0004 & -0.0003 \\
& $(0.0034)$ & $(-0.0001)$ & $(0.0005)$ & $(0.0008)$ & $(0.0007)$ & $(0.00001)$ \\
\hline $\boldsymbol{p}$-value & $9 \times 10^{-10}$ & $1 \times 10^{-4}$ & $9 \times 10^{-5}$ & 0.002 & 0.0032 & 0.0014 \\
\hline
\end{tabular}

(a)



(b)



Figure 12: (a) true color image composite of HICO's TOA radiance at 461, 553, and $639 \mathrm{~nm}$ of the Chesapeake Bay. (b) true color image composite of $\mathrm{HICO}$ at the Gulf of Mexico.

The results in Fig. 13 show the map and histogram comparisons of [Chl] and $R_{r s}$ at 443, 488, and 560 $\mathrm{nm}$ retrieved at the Chesapeake Bay by the NASA's standard three-band empirical band ratio algorithm (OC3) (O'Reilly et al., 1998, 2000) as compared to co-incident, co-located MODISA OC3 retrievals. The time difference of the acquisition between the two scenes is nearly 2.5 hours.

Notably, the average agreement in [Chl] between the two scenes is very good, with HICO showing more spatial details due to the higher native resolution as compared to the 1-km MODISA pixel. The agreement in [Chl] of the highly dynamic inland estuaries is less noticeable, which can be due to the time difference between MODISA and HICO scene acquisition. Spatial anomalies in HICO's [Chl] image can be apparent such as the feature of increased [Chl] across the bay area. That anomaly is attributed to erroneous [Chl] retrieval due to the increased contribution of reflectance backscattered from the Lucuius J. Kellam Jr. Bridge-Tunnel across the mouth of the Bay. The high spatial resolution in HICO was able to discern the man-made structure, whereas MODISA's image shows much less sensitivity due to the high spatial averaging over $1 \mathrm{~km}$ pixels.

Similar to the Chesapeake Bay analysis, we show the retrievals and comparisons between a HICO scene at 




Figure 13: A comparison of [Chl] retrieval between MODISA (right map) and HICO (left map) in the Chesapeake Bay and histogram comparisons of [Chl] and $R_{r s}$ at 443,488 , and $560 \mathrm{~nm}$, used in the OC3 algorithm.

a coastal region in the Gulf of Mexico and MODISA. Fig. 14 shows the chlorophyll concentration retrievals of HICO and MODISA for the same co-located scene and histogram comparisons of the [Chl] and $R_{r s}$ at 443 , 490, and $560 \mathrm{~nm}$ used for the OC3 [Chl] algorithm. The time difference between the two scenes is nearly 1.5 hours. The spatial variability and magnitude of the [Chl] are quite similar for both sensors, and HICO shows more details regarding the spatial structure of phytoplankton blooms in the area as compared to MODISA, since it's not down-sampled. The high native spatial resolution advantage in HICO allows a better distinction to the blooms' spatial structure even when HICO was spatially averaged to a $1 \mathrm{~km}$ resolution. Across the shoreline, the MODISA retrievals show higher [Chl] than HICO at some pixels. This could be due to the spatially averaged bright land pixels (i.e., ephemeral impact) and the impact of the sandy benthos of the shallow waters. Statistically, there is a strong agreement in both $R_{r s}$ and [Chl].

For a more detailed spectral analysis, Fig. 15 (a) shows the hyperspectral $R_{r s}$ retrieved from HICO and the multi-spectral MODISA retrievals at three stations in the image from the Chesapeake Bay, while Fig. 15 (b) is the same as (a) but for the Gulf of Mexico scene. We selected these locations since they represent three different water types and [Chl]. In Fig. 15 (a), ST1 is located in the York River, a highly turbid, highly productive region. ST2 is located at the mouth of the Chesapeake Bay and ST3 is just outside the bay in the Atlantic Ocean. In Fig. 15 (b) ST1 is located in eastern Choctawhatchee Bay, ST2 is in near the 

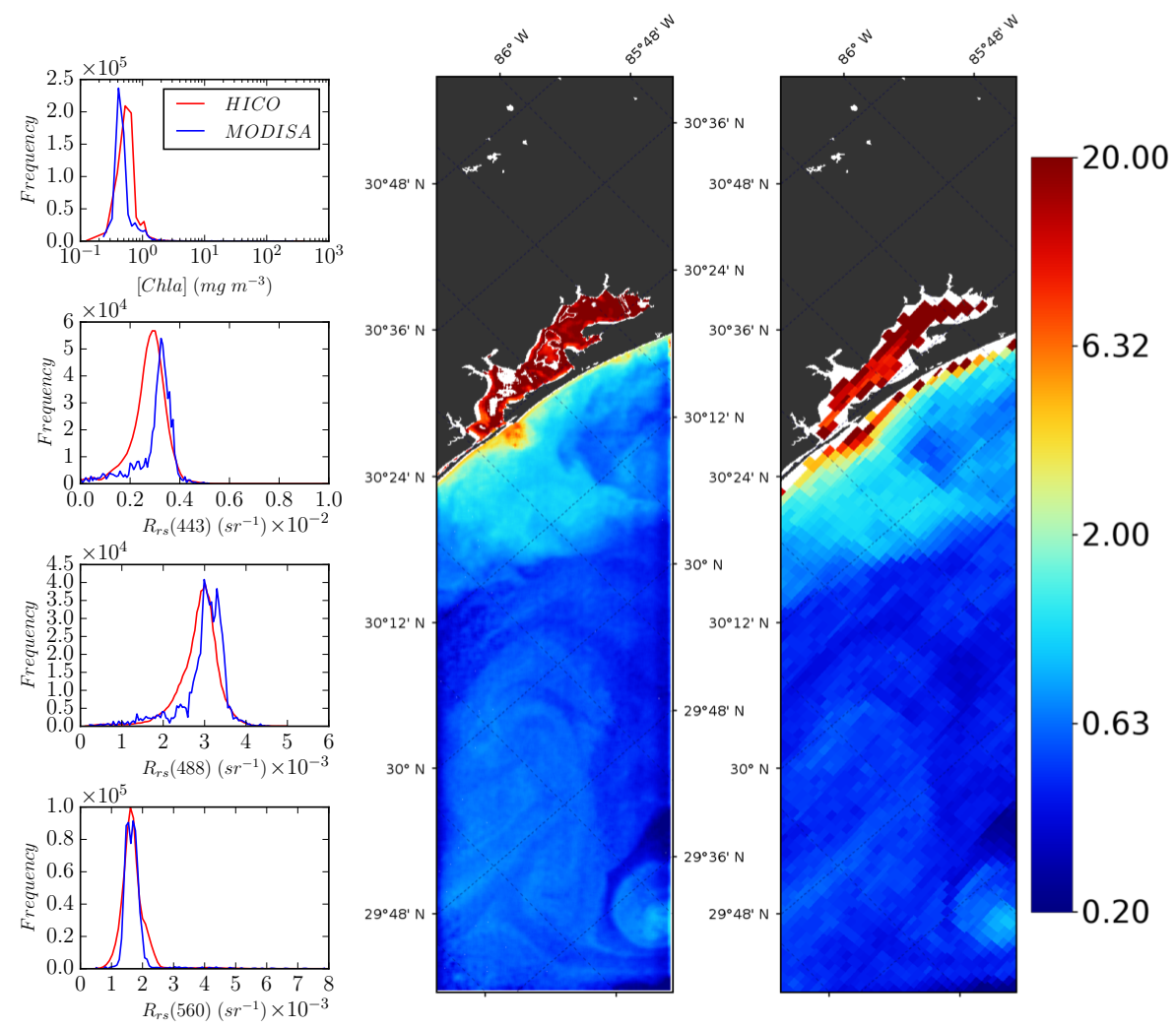

$-6.32$



Figure 14: A comparison of [Chl] retrieval between MODISA (right map) and HICO (left map) in the Gulf of Mexico and histogram comparisons of [Chl] and $R_{r s}$ at 443,488 , and $560 \mathrm{~nm}$, used in the OC3 algorithm.

coast in the middle of a phytoplankton bloom, and ST3 is further away from the coast in a relatively clearer Gulf water.

The agreement between MODISA and HICO $R_{r s}$ retrieval is very good for the three locations, indicating good consistency in algorithm performance regardless of the water type. Fig. 15 also demonstrates the spectral features that HICO can resolve as compared to the multi-spectral MODISA. In Fig. 15 (b), the agreement between MODISA and HICO is very good as well, similar to the Chesapeake Bay case. The retrieval at ST1 shows unphysically negative $R_{r s}$ values in the blue channels for HICO and for MODISA at $412 \mathrm{~nm}$. The unphysical value may be attributable to the problematic atmospheric correction over highly turbid waters that nullify the black pixel assumption in the NIR and therefore overestimate the aerosol contribution. Although, the NIR correction algorithm of non-black pixel was applied to the image, the bio-optical mode in the algorithm doesn't work in those extreme turbid conditions (Bailey et al., 2010). It is also possible that the scene is contaminated with absorbing aerosols, which cannot be detected with HICO or MODISA spectral capabilities, or impacted by adjacency effects or benthic effects. Such cases of high turbidity or complexity are extreme and represent less than a few percent of the global ocean. These scenarios can be potentially addressed with some increasing spectral capabilities by utilizing UV channels, 



Figure 15: (a) and (b) is the comparison of the spectral $R_{r s}$ between MODISA (dashed lines) and HICO (solid lines) retrievals at three locations in the Chesapeake Bay, and the Gulf of Mexico, respectively.

or with polarimetric observations, as planned for the PACE mission.

\section{Conclusion}

Hyperspectral atmospheric correction was developed and integrated into NASA's multispectral atmospheric correction code, L2GEN. The extension of the algorithm allowed the compensation of absorbing gases in the atmosphere, mainly for the water vapor, and the correction of Rayleigh and aerosol scattering over the visible hyperspectral range. The algorithm was tested and validated with the HICO sensor, where retrievals of the hyperspectral $R_{r s}$ and [Chl] were compared to in-situ measurements and MODISA retrievals. HICO's $R_{r s}$ retrievals didn't show spectral features attributed to the absorbing gases, indicating a proper compensation in the atmospheric correction. In order to provide ocean color products, the vicarious calibration process was applied to HICO based on MOBY's in-situ measurements. Hyperspectral vicarious gains were derived and applied, and $R_{r s}$ retrieval performance was assessed relative to in situ match-ups from SeaBASS and AERONET-OC. We also showed two study cases where HICO scenes at the Chesapeake Bay and the Gulf of Mexico are compared to MODISA retrievals. The qualitative and quantitative indicators showed a very good agreement with MODISA and in-situ measurements, providing confidence in the hyperspectral $R_{r s}$ and derived ocean color products retrieved from HICO observations. This study also provides support for atmospheric correction and ocean color algorithm development for the PACE mission, where HICO data can serve as a proxy data for hyperspectral algorithm development and testing. The full hyperspectral AC algorithm is currently available through SeaDAS version 7.4 and is publicly available through https://oceancolor.gsfc.nasa.gov/. HICO Level-2 scenes will also be available for the community in the near future. 


\section{Funding}

NASA's Plankton, Aerosol, Cloud, ocean Ecosystem (PACE) science team.

\section{Acknowledgement}

We would like to acknowledge our colleague Richard Healy, who passed away in late 2016. Richard was an integral part of this work and a dear colleague to the Ocean Ecology Lab at NASA Goddard Space Flight Center. We are forever grateful for his dedication and contributions. We acknowledge our thanks to the MOBY team of NOAA for providing the in-situ MOBY radiometry and Giuseppe Zibordi and other AERONET-OC PIs for their data.

\section{References}

Ahmad, Z., Franz, B.A., McClain, C.R., Kwiatkowska, E.J., Werdell, J., Shettle, E.P., Holben, B.N., 2010. New aerosol models for the retrieval of aerosol optical thickness and normalized water-leaving radiances from the SeaWiFS and MODIS sensors over coastal regions and open oceans. Appl. Opt. 49, 5545. doi:10.1364/AO.49.005545

Ahmad, Z., Fraser, R.S., 1982. An Iterative Radiative Transfer Code For Ocean-Atmosphere Systems. J. Atmospheric Sci. 39, 656?665. doi:10.1175/1520-0469(1982)039<0656:AIRTCF $>2$

$.0 . \mathrm{CO} ; 2$

Ahmad, Z., McClain, C.R., Herman, J.R., Franz, B.A., Kwiatkowska, E.J., Robinson, W.D., Bucsela, E.J., Tzortziou, M., 2007. Atmospheric correction for NO2 absorption in retrieving water-leaving reflectances from the SeaWiFS and MODIS measurements. Appl. Opt. 46, 6504?6512.

Anderson, G.P., Clough, S.A., Kneizys, F.X., Chetwynd, J.H., Shettle, E.P., 1986. AFGL atmospheric constituent profiles (0 - 120 km), AFGL-TR-86-0110. U.S. Air Force Geophysics Laboratory. Optical Physics Division.

Bailey, S.W., Franz, B.A., Werdell, P.J., 2010. Estimation of near-infrared water-leaving reflectance for satellite ocean color data processing. Opt. Express 18, 7521. doi:10.1364/OE.1

8.007521

Bodhaine, B.A., Wood, N.B., Dutton, E.G., Slusser, J.R., 1999. On Rayleigh Optical Depth Calculations. J. Atmospheric Ocean. Technol. 16, 1854?1861. doi:10.1175/1520-0426(1999)016¡1854:ORODC¿2.0.CO;2

Braslau, N., Dave, J.V., 1973. Effect of Aerosols on the Transfer of Solar Energy Through Realistic Model Atmospheres. Part I: Non-Absorbing Aerosols. J. Appl. Meteorol. 12, 601?615. doi:10.1175/15200450(1973)012;0601:EOAOTT¿2.0.CO;2 
Clark, D.K., Gordon, H.R., Voss, K.J., Ge, Y., Broenkow, W., Trees, C., 1997. Validation of atmospheric correction over the oceans. J. Geophys. Res. Atmospheres 102, 17209?17217. doi:10.1029/96JD03345

Corson, M.R., Korwan, D.R., Lucke, R.L., Snyder, W.A., Davis, C.O., 2008. The Hyperspectral Imager for the Coastal Ocean (HICO) on the International Space Station, in: IGARSS 2008 - 2008 IEEE International Geoscience and Remote Sensing Symposium. Presented at the IGARSS 2008 - 2008 IEEE International Geoscience and Remote Sensing Symposium, p. IV-101-IV-104. doi:10.1109/IGARSS.2008.4779666

Corson, M.R., Lucke, R.L., Davis, C.O., Bowles, J.H., Chen, D.T., Gao, B.C., Korwan, D.R., Miller, W.D., Snyder, W.A., 2010. The Hyperspectral Imager for the Coastal Ocean (HICO \#x2122;) environmental littoral imaging from the International Space Station, in: Geoscience and Remote Sensing Symposium (IGARSS), 2010 IEEE International. Presented at the Geoscience and Remote Sensing Symposium (IGARSS), 2010 IEEE International, pp. 3752?3755. doi:10.1109/IGARSS.2010.5651830

Cox, C., Munk, W., 1954. Measurement of the Roughness of the Sea Surface from Photographs of the Sun?s Glitter. JOSA 44, 838?850. doi:10.1364/JOSA.44.000838

Dee, D.P., Uppala, S.M., Simmons, A.J., Berrisford, P., Poli, P., Kobayashi, S., Andrae, U., Balmaseda, M.A., Balsamo, G., Bauer, P., Bechtold, P., Beljaars, A.C.M., van de Berg, L., Bidlot, J.,

Bormann, N., Delsol, C., Dragani, R., Fuentes, M., Geer, A.J., Haimberger, L., Healy, S.B., Hersbach, H., Hlm, E.V., Isaksen, L., Kllberg, P., Khler, M., Matricardi, M., McNally, A.P., Monge-Sanz,

B.M., Morcrette, J.-J., Park, B.-K., Peubey, C., de Rosnay, P., Tavolato, C., Thpaut, J.-N., Vitart, F., 2011. The ERA-Interim reanalysis: configuration and performance of the data assimilation system. Q. J. R. Meteorol. Soc. 137, 553?597. doi:10.1002/qj.828

Derber, J.C., Parrish, D.F., Lord, S.J., 1991. The New Global Operational Analysis System at the National Meteorological Center. Weather Forecast. 6, 538?547. doi:10.1175/1520-0434(1991)006;0538:TNGOAS ¿2.0.CO;2

Donlon, C., Berruti, B., Buongiorno, A., Ferreira, M.-H., Fmnias, P., Frerick, J., Goryl, P., Klein, U., Laur, H., Mavrocordatos, C., Nieke, J., Rebhan, H., Seitz, B., Stroede, J., Sciarra, R., 2012. The Global Monitoring for Environment and Security (GMES) Sentinel-3 mission. Remote Sens. Environ., The Sentinel Missions - New Opportunities for Science 120, 37?57. doi:10.1016/j.rse.2011.07.024

Dubuisson, P., Borde, R., Schmechtig, C., Santer, R., 2001. Surface pressure estimates from satellite data in the oxygen A-band: Applications to the MOS sensor over land. J. Geophys. Res. Atmospheres 106, 27277?27286. doi:10.1029/2001JD000401

Dubuisson, P., Dessailly, D., Vesperini, M., Frouin, R., 2004. Water vapor retrieval over ocean using near-infrared radiometry. J. Geophys. Res. Atmospheres 109, D19106. doi:10.1029/2004JD004516

Emde, C., Buras-Schnell, R., Kylling, A., Mayer, B., Gasteiger, J., Hamann, U., Kylling, J., Richter, B., Pause, C., Dowling, T., Bugliaro, L., 2016. The libRadtran software package for radiative transfer 
calculations (version 2.0.1). Geosci Model Dev 9, 1647?1672. doi:10.5194/gmd-9-1647-2016

Esaias, W.E., Abbott, M.R., Barton, I., Brown, O.B., Campbell, J.W., Carder, K.L., Clark, D.K., Evans, R.H., Hoge, F.E., Gordon, H.R., Balch, W.M., Letelier, R., Minnett, P.J., 1998. An overview of MODIS capabilities for ocean science observations. IEEE Trans. Geosci. Remote Sens. 36, 1250?1265. doi:10.1109/36.701076

Franz, B.A., Bailey, S.W., Werdell, P.J., McClain, C.R., 2007. Sensor-independent approach to the vicarious calibration of satellite ocean color radiometry. Appl. Opt. 46, 5068. doi:10.1364/AO.46.005068

Frouin, R., Deschamps, P.-Y., Lecomte, P., 1990. Determination from Space of Atmospheric Total Water Vapor Amounts by Differential Absorption near 940 nm: Theory and Airborne Verification. J. Appl. Meteorol. 29, 448?460. doi:10.1175/1520-0450(1990)029<044

8:DFSOAT $>2.0 . \mathrm{CO} ; 2$

Frouin, R., Schwindling, M., Deschamps, P.-Y., 1996. Spectral reflectance of sea foam in the visible and near-infrared: In situ measurements and remote sensing implications. J. Geophys. Res. Oceans 101, 14361-14371. doi:10.1029/96JC00629

Gao, B.-C., Davis, C.O., 1997. Development of a line-by-line-based atmosphere removal algorithm for airborne and spaceborne imaging spectrometers. pp. 132?141. doi:10.1117/12.28 3822

Gao, B.-C., Goetz, A.F.H., Westwater, E.R., Conel, J.E., Green, R.O., 1993a. Possible Near-IR Channels for Remote Sensing Precipitable Water Vapor from Geostationary Satellite Platforms. J. Appl. Meteorol. 32, 1791-1801. doi:10.1175/1520-0450(1993)032<1791:PNICF

$\mathrm{R}>2.0 . \mathrm{CO} ; 2$

Gao, B.-C., Heidebrecht, K.B., Goetz, A.F.H., 1993b. Derivation of scaled surface reflectances from AVIRIS data. Remote Sens. Environ. 44, 165?178. doi:10.1016/0034-4257(93)90014-O

Gao, B.-C., Kaufman, Y.J., 2003. Water vapor retrievals using Moderate Resolution Imaging Spectroradiometer (MODIS) near-infrared channels. J. Geophys. Res. Atmospheres 108, 4389. doi:10.1029/2002JD003023

Gao, B.-C., Li, R.-R., 2010. Spectral calibrations of HICO data using atmospheric bands and radiance adjustment based on HICO and MODIS data comparisons, in: Geoscience and Remote Sensing Symposium (IGARSS), 2010 IEEE International. Presented at the Geoscience and Remote Sensing Symposium (IGARSS), 2010 IEEE International, pp. 4260?4263. doi:10.1109/IGARSS.2010.5649146

Gao, B.-C., Li, R.-R., Lucke, R.L., Davis, C.O., Bevilacqua, R.M., Korwan, D.R., Montes, M.J., Bowles, J.H., Corson, M.R., 2012. Vicarious calibrations of HICO data acquired from the International Space Station. Appl. Opt. 51, 2559. doi:10.1364/AO.51.002559

Gao, B.-C., Montes, M.J., Ahmad, Z., Davis, C.O., 2000. Atmospheric correction algorithm for hyper- 
spectral remote sensing of ocean color from space. Appl. Opt. 39, 887. doi:10.1364/AO.39.000887

Gao, B.-C., Montes, M.J., Davis, C.O., Goetz, A.F.H., 2009. Atmospheric correction algorithms for hyperspectral remote sensing data of land and ocean. Remote Sens. Environ., Imaging Spectroscopy Special Issue 113, Supplement 1, S17?S24. doi:10.1016/j.rse.2007.12.015

Gordon, H.R., Boynton, G.C., Balch, W.M., Groom, S.B., Harbour, D.S., Smyth, T.J., 2001. Retrieval of coccolithophore calcite concentration from SeaWiFS Imagery. Geophys. Res. Lett. 28, 1587?1590. doi:10.1029/2000GL012025

Gordon, H.R., Wang, M., 1994a. Retrieval of water-leaving radiance and aerosol optical thickness over the oceans with SeaWiFS: a preliminary algorithm. Appl. Opt. 33, 443. doi:10.1364/AO.33.000443

Gordon, H.R., Wang, M., 1994b. Influence of oceanic whitecaps on atmospheric correction of ocean-color sensors. Appl. Opt. 33, 7754?7763. doi:10.1364/AO.33.007754 IOCCG (2014). Phytoplankton Functional Types from Space, 2014.

Kanamitsu, M., Ebisuzaki, W., Woollen, J., Yang, S.-K., Hnilo, J.J., Fiorino, M., Potter, G.L., 2002. NCEP?DOE AMIP-II Reanalysis (R-2). Bull. Am. Meteorol. Soc. 83, 1631?1643. doi:10.1175/BAMS-83$11-1631$

Kato, S., Ackerman, T.P., Mather, J.H., Clothiaux, E.E., 1999. The k-distribution method and correlatedk approximation for a shortwave radiative transfer model. J. Quant. Spectrosc. Radiat. Transf. 62, 109?121. doi:10.1016/S0022-4073(98)00075-2

Kaufman, Y.J., Gao, B.-C., 1992. Remote sensing of water vapor in the near IR from EOS/MODIS. IEEE Trans. Geosci. Remote Sens. 30, 871?884. doi:10.1109/36.175321

Koepke, P., 1984. Effective reflectance of oceanic whitecaps. Appl. Opt. 23, 1816?1824. doi:10.1364/AO.23.001816

Korwan, D.R., Lucke, R.L., McGlothlin, N.R., Butcher, S.D., Wood, D.L., Bowles, J.H., Corson, M., Snyder, W.A., Davis, C.O., Chen, D.T., 2009. Laboratory characterization of the Hyperspectral Imager for the Coastal Ocean (HICO), in: 2009 IEEE International Geoscience and Remote Sensing Symposium. Presented at the 2009 IEEE International Geoscience and Remote Sensing Symposium, p. II-69-II-72. doi:10.1109/IGARSS.2009.5418003

Kudela, R.M., Palacios, S.L., Austerberry, D.C., Accorsi, E.K., Guild, L.S., Torres-Perez, J., 2015. Application of hyperspectral remote sensing to cyanobacterial blooms in inland waters. Remote Sens. Environ., Special Issue on the Hyperspectral Infrared Imager (HyspIRI) 167, 196?205. doi:10.1016/j.rse.2015.01.025

Lacis, A.A., Oinas, V., 1991. A description of the correlated $\mathrm{k}$ distribution method for modeling nongray gaseous absorption, thermal emission, and multiple scattering in vertically inhomogeneous atmospheres. J. Geophys. Res. Atmospheres 96, 9027?9063. doi:10.1029/90JD01945

Lubac, B., Loisel, H., Guiselin, N., Astoreca, R., Felipe Artigas, L., Mriaux, X., 2008. Hyperspectral and 
multispectral ocean color inversions to detect Phaeocystis globosa blooms in coastal waters. J. Geophys. Res. Oceans 113, C06026. doi:10.1029/2007JC004451

Lucke, R.L., Corson, M., McGlothlin, N.R., Butcher, S.D., Wood, D.L., Korwan, D.R., Li, R.R., Snyder, W.A., Davis, C.O., Chen, D.T., 2011. Hyperspectral Imager for the Coastal Ocean: instrument description and first images. Appl. Opt. 50, 1501. doi:10.1364/AO.50.001 501

Mayer, B., 2009. Radiative transfer in the cloudy atmosphere. EPJ Web Conf. 1, 75?99. doi:10.1140/epjconf/e200900912-1

McClain, C.R., Feldman, G.C., Hooker, S.B., 2004. An overview of the SeaWiFS project and strategies for producing a climate research quality global ocean bio-optical time series. Deep Sea Res. Part II Top. Stud. Oceanogr. 51, 5?42. doi:10.1016/j.dsr2.2003.11.001

Meister, G., Franz, B.A., Kwiatkowska, E.J., McClain, C.R., 2010. Corrections to the calibration of MODIS Aqua ocean color bands derived from SeaWiFS data, in: 2010 IEEE International Geoscience and Remote Sensing Symposium. Presented at the 2010 IEEE International Geoscience and Remote Sensing Symposium, pp. 3688?3691. doi:10.1109/IGARSS.201

0.5651742

Morel, A., Antoine, D., Gentili, B., 2002. Bidirectional reflectance of oceanic waters: accounting for Raman emission and varying particle scattering phase function. Appl. Opt. 41, 6289?6306. doi:10.1364/AO.41.006289

Morel, A., Maritorena, S., 2001. Bio-optical properties of oceanic waters: A reappraisal. J. Geophys. Res. Oceans 106, 7163?7180. doi:10.1029/2000JC000319

Murphy, R.E., Barnes, W.L., Lyapustin, A.I., Privette, J., Welsch, C., DeLuccia, F., Swenson, H., Schueler, C.F., Ardanuy, P.E., Kealy, P.S.M., 2001. Using VIIRS to provide data continuity with MODIS, in: IGARSS 2001. Scanning the Present and Resolving the Future. Proceedings. IEEE 2001 International Geoscience and Remote Sensing Symposium (Cat. No.01CH37217). Presented at the IGARSS 2001. Scanning the Present and Resolving the Future. Proceedings. IEEE 2001 International Geoscience and Remote Sensing Symposium (Cat. No.01CH37217), pp. 1212?1214 vol.3. doi:10.1109/IGARSS.2001.976795

Nair, A., Sathyendranath, S., Platt, T., Morales, J., Stuart, V., Forget, M.-H., Devred, E., Bouman, H., 2008. Remote sensing of phytoplankton functional types. Remote Sens. Environ., Earth Observations for Marine and Coastal Biodiversity and Ecosystems Special Issue 112, 3366?3375. doi:10.1016/j.rse.2008.01.021

O’Reilly, J.E., Maritorena, S., Mitchell, B.G., Siegel, D.A., Carder, K.L., Garver, S.A., Kahru, M., McClain, C., 1998. Ocean color chlorophyll algorithms for SeaWiFS. J. Geophys. Res. Oceans 103, 24937?24953. doi:10.1029/98JC02160

O’Reilly, J.E., Maritorena, S., Mueller, J., Mitchell, B.G., Kahru, M., Chavez, F.P., Strutton, P., 2000. 
SeaWiFS Postlaunch Calibration and Validation Analyses, Part 3 (No. 11), Technical Report Series.

Pre-Aerosol, Clouds, and ocean Ecosystem (PACE) Mission Science Definition Team Report, 2012.

Rast, M., Bezy, J.L., Bruzzi, S., 1999. The ESA Medium Resolution Imaging Spectrometer MERIS a review of the instrument and its mission. Int. J. Remote Sens. 20, 1681?1702. doi:10.1080/014311699212416

Rothman, L.S., Gordon, I.E., Babikov, Y., Barbe, A., Chris Benner, D., Bernath, P.F., Birk, M., Bizzocchi, L., Boudon, V., Brown, L.R., Campargue, A., Chance, K., Cohen, E.A., Coudert, L.H., Devi, V.M., Drouin, B.J., Fayt, A., Flaud, J.-M., Gamache, R.R., Harrison, J.J., Hartmann, J.-M., Hill, C., Hodges, J.T., Jacquemart, D., Jolly, A., Lamouroux, J., Le Roy, R.J., Li, G., Long, D.A., Lyulin, O.M., Mackie, C.J., Massie, S.T., Mikhailenko, S., Mller, H.S.P., Naumenko, O.V., Nikitin, A.V., Orphal, J., Perevalov, V., Perrin, A., Polovtseva, E.R., Richard, C., Smith, M.A.H., Starikova, E., Sung, K., Tashkun, S., Tennyson, J., Toon, G.C., Tyuterev, V.G., Wagner, G., 2013. The HITRAN2012 molecular spectroscopic database. J. Quant. Spectrosc. Radiat. Transf., HITRAN2012 special issue 130, 4?50. doi:10.1016/j.jqsrt.2013.07.002

Ruddick, K.G., Ovidio, F., Rijkeboer, M., 2000. Atmospheric correction of SeaWiFS imagery for turbid coastal and inland waters. Appl. Opt. 39, 897. doi:10.1364/AO.39.000897

Ryan, J.P., Davis, C.O., Tufillaro, N.B., Kudela, R.M., Gao, B.-C., 2014. Application of the Hyperspectral Imager for the Coastal Ocean to Phytoplankton Ecology Studies in Monterey Bay, CA, USA. Remote Sens. 6, 1007?1025. doi:10.3390/rs6021007

SeaWiFS Data Analysis System (SeaDAS) [WWW Document], 2017. URL https://seadas .gsfc.nasa.gov (accessed 1.1.17).

Sun, J.Q., Xiong, X., Barnes, W.L., Guenther, B., 2007. MODIS Reflective Solar Bands On-Orbit Lunar Calibration. IEEE Trans. Geosci. Remote Sens. 45, 2383?2393. doi:10.1109/TGRS.2007.896541

Thuillier, G., Hers, M., Labs, D., Foujols, T., Peetermans, W., Gillotay, D., Simon, P.C., Mandel, H., 2003. The Solar Spectral Irradiance from 200 to $2400 \mathrm{~nm}$ as Measured by the SOLSPEC Spectrometer from the Atlas and Eureca Missions. Sol. Phys. 214, 1?22. doi:10.1023/A:1024048429145

Tomasi, C., Vitale, V., Petkov, B., Lupi, A., Cacciari, A., 2005. Improved algorithm for calculations of Rayleigh-scattering optical depth in standard atmospheres. Appl. Opt. 44, 3320?3341. doi:10.1364/AO.44.003320

Wang, M., Son, S., Shi, W., 2009. Evaluation of MODIS SWIR and NIR-SWIR atmospheric correction algorithms using SeaBASS data. Remote Sens. Environ. 113, 635?644. doi:10.1016/j.rse.2008.11.005

Werdell, J., 2016. The NASA Plankton, Aerosol, Cloud, ocean Ecosystem (PACE) mission. Presented at the Ocean Optics XXIII, Victoria, BC, Canada.

Werdell, J., Bailey, S.W., Fargion, G., McClain, C.R., 2002. The SeaWiFS Bio-optical Archive and Storage System (SeaBASS): Current architecture and implementation, NASA Tech. Memo. 2002-211617.

Werdell, P.J., Bailey, S.W., 2005. An improved in-situ bio-optical data set for ocean color algorithm devel- 
opment and satellite data product validation. Remote Sens. Environ. 98, 122?140. doi:10.1016/j.rse.2005.07.001

Xiong, X., Sun, J., Xie, X., Barnes, W.L., Salomonson, V.V., 2010. On-Orbit Calibration and Performance of Aqua MODIS Reflective Solar Bands. IEEE Trans. Geosci. Remote Sens. 48, $535 ? 546$. doi:10.1109/TGRS.2009.2024307

Zhai, P.-W., Hu, Y., Chowdhary, J., Trepte, C.R., Lucker, P.L., Josset, D.B., 2010. A vector radiative transfer model for coupled atmosphere and ocean systems with a rough interface. J. Quant. Spectrosc. Radiat. Transf. 111, 1025?1040. doi:10.1016/j.jqsrt.2009.12.005

Zhai, P.-W., Hu, Y., Trepte, C.R., Lucker, P.L., 2009. A vector radiative transfer model for coupled atmosphere and ocean systems based on successive order of scattering method. Opt. Express 17, $2057 ? 2079$. doi:10.1364/OE.17.002057

Zhai, P.-W., Hu, Y., Winker, D.M., Franz, B.A., Boss, E., 2015. Contribution of Raman scattering to polarized radiation field in ocean waters. Opt. Express 23, 23582?23596. doi:10.1364/OE.23.023582

Zhai, P.-W., Hu, Y., Winker, D.M., Franz, B.A., Werdell, J., Boss, E., 2017. Vector radiative transfer model for coupled atmosphere and ocean systems including inelastic sources in ocean waters. Opt. Express 25, A223?A239. doi:10.1364/OE.25.00A223

Zibordi, G., Mlin, F., Berthon, J.-F., Holben, B., Slutsker, I., Giles, D., D'Alimonte, D., Vandemark, D., Feng, H., Schuster, G., Fabbri, B.E., Kaitala, S., Seppala, J., 2009. AERONET-OC: A Network for the Validation of Ocean Color Primary Products. J. Atmospheric Ocean. Technol. 26,1634 ?1651. doi:10.1175/2009JTECHO654.1

\section{Appendix}


Table A1: HICO's hyperspectral gains derived from the vicarious calibration

\begin{tabular}{cccc}
\hline $\begin{array}{c}\text { Wavelength } \\
(\mathbf{n m})\end{array}$ & $\begin{array}{c}\text { Gain } \\
\text { factors }\end{array}$ & $\begin{array}{c}\text { Wavelength } \\
(\mathbf{n m})\end{array}$ & $\begin{array}{c}\text { Gain } \\
\text { factors }\end{array}$ \\
\hline 404 & 1.042 & 605 & 1.038 \\
409 & 1.012 & 610 & 1.038 \\
415 & 1.009 & 616 & 1.038 \\
421 & 1.025 & 622 & 1.050 \\
426 & 1.034 & 627 & 1.060 \\
432 & 1.017 & 633 & 1.063 \\
438 & 1.019 & 639 & 1.063 \\
444 & 1.028 & 645 & 1.058 \\
450 & 1.035 & 650 & 1.057 \\
456 & 1.046 & 656 & 1.046 \\
461 & 1.051 & 662 & 1.044 \\
467 & 1.044 & 668 & 1.043 \\
473 & 1.041 & 673 & 1.041 \\
479 & 1.041 & 679 & 1.041 \\
484 & 1.023 & 685 & 1.023 \\
490 & 1.013 & 690 & 1.026 \\
496 & 1.020 & 696 & 1.063 \\
501 & 1.013 & 702 & 1.076 \\
507 & 1.013 & 708 & 1.072 \\
513 & 1.000 & 713 & 1.069 \\
519 & 0.991 & 719 & 1.058 \\
524 & 0.993 & 725 & 1.059 \\
530 & 0.998 & 731 & 1.066 \\
536 & 1.006 & 736 & 1.059 \\
542 & 1.014 & 742 & 1.052 \\
547 & 1.020 & 747 & 1.038 \\
553 & 1.021 & 753 & 1.022 \\
559 & 1.015 & 759 & 0.986 \\
564 & 1.016 & 765 & 0.973 \\
570 & 1.028 & 771 & 0.995 \\
576 & 1.038 & 776 & 1.000 \\
582 & 1.039 & 782 & 1.005 \\
587 & 1.036 & 787 & 1.000 \\
593 & 1.033 & 794 & 0.992 \\
599 & 1.038 & 799 & 0.981 \\
\hline & & &
\end{tabular}

